\title{
O RECONHECIMENTO DO CARÁTER BIFRONTE DA ÁGUA: DIREITO HUMANO E DA NATUREZA
}

\section{THE RECOGNITION OF DUAL CHARACTER OF WATER: HUMAN RIGHT AND OF THE NATURE}

\author{
${ }^{1}$ William Paiva Marques Júnior
}

\section{RESUMO}

A água transcende o status de direito humano, sendo também reconhecida como direito da natureza. A conformação do direito humano à água potável é corolário das reivindicações sociais plasmadas pelas Cartas Constitucionais da Bolívia e Equador, que se irradiou por todo o Planeta a partir da Resolução da Assembleia Geral da ONU A/RES/64/292/2010. A pesquisa tem por escopo a perquirição do reconhecimento do acesso à água potável como direito humano e como direito da natureza, conforme propugnado pelo Novo Constitucionalismo Democrático Latino-Americano ante um contexto de escassez e necessidade de valorização dos recursos aquíferos para a vida no Planeta Terra.

Palavras-chave: Direito humano, Água, Direitos da natureza, Caráter bifronte

\begin{abstract}
The water transcends the status of human rights, also being recognized as a right of nature. The conformation of the human right to drinking water is a corollary of social demands molded by Letters Constitutional of Bolivia and Ecuador, which has spread across the planet from the UN General Assembly resolution RES / 64/292/2010. The research has scope to investigate the recognition of access to drinking water as a human right and right of nature, advocated by the New Constitutionalism Democratic Latin American against a context of scarcity and need for enhancement of water resources for life on Planet Earth.
\end{abstract}

Keywords: Human right, Water, Rights of nature, Dual character

${ }^{1}$ Doutor em Direito Constitucional pela Universidade Federal do Ceará - UFC, Fortaleza, (Brasil). Professor Assistente do Departamento de Direito Privado da Universidade Federal do Ceará - UFC. E-mail: tutortreinamento@gmail.com 


\section{INTRODUÇÃO}

O direito à água potável e ao saneamento básico tem recebido, seja no plano internacional, em diversos tratados e convenções, seja no âmbito interno, em constituições de vários países, o tratamento de legítimo direito humano fundamental, na medida em que aumenta a consciência de seu caráter essencial para a manutenção da dignidade da pessoa humana (base axiológica dos direitos fundamentais). Em 28 de Julho de 2010 a Assembleia Geral das Nações Unidas através da Resolução A/RES/64/292 declarou a água potável e o saneamento básico como um direito humano essencial para o gozo pleno da vida e de todos os outros direitos humanos.

O tratamento jurídico dos recursos hídricos propugnado pelo Novo Constitucionalismo Democrático Latino-Americano funda-se na cultura do buen vivir oriunda dos povos ameríndios autóctones como sendo parte integrante de um direito da natureza.

Com base em uma epistemologia de cunho sócio-biocêntrico, os direitos da natureza encontram-se em um estádio mais avançado dos direitos humanos reconhecidos pelo Neoconstitucionalismo. Neste sentido, para além de assegurarem os direitos dos seres humanos aos recursos aquíferos, o enfoque prioritário será a Mãe Natureza como um todo. Neste jaez, observa-se que o acesso à água, o qual, diferente do que se pode compreender em primeira evidência, não exclui o ser humano desse direito, a despeito de retirá-lo do enfoque prioritário.

Ademais, as Constituições do Equador (2008) e da Bolívia (2009) proíbem, expressamente, a privatização da água, avanço que ainda não foi incorporado em documentos internacionais que tratam do tema. Neste jaez, deve-se ressalvar que, apesar da realidade sul-americana ainda se encontrar distante da ordem internacional, por se centrar em outras premissas, como a pluralismo epistemológico e a ecologia profunda, acaba por permitir a reflexão da crise no acesso à água, da justiça ambiental e da atuação do Direito em relação a ela sob outros matizes ideológicos, visando a ampliação da percepção ambiental sobre o tema.

Por essa razão, se desperta para a importância da normatização e da definição de políticas de gestão dos recursos hídricos. A gestão inconsequente, desastrosa e irresponsável das águas, da qual resultaram danos irreversíveis, como por exemplo, a desertificação de grandes áreas terrestres e bruscas mudanças climáticas, 
cede lugar, paulatinamente, a uma abordagem ambiental, social e econômica do uso e da preservação dos recursos hídricos da Terra.

Ao longo deste estudo, perquirir-se-á transversalmente acerca de fatores naturais, ambientais, históricos, filosóficos, políticos e jurídicos, a partir dos quais se configurou um viés mutacional na problemática da gestão dos recursos hídricos nos países da América do Sul, continente depositário da maior reserva de águas doces do planeta, em especial nos sistemas jurídicos do Brasil, do Equador e da Bolívia.

A escassez da água demonstra que se trata de um recurso natural limitado. Comparando a situação brasileira com a planetária verifica-se que o país apresenta uma extensa rede hidrográfica, com seis grandes bacias, tais como: Amazonas, Tocantins, São Francisco, Paraná, Paraguai e Uruguai, além de condições climáticas adequadas que permitem o abastecimento por meio das chuvas. Não existe uma conscientização da utilização das águas no Planeta e a importância de seu estudo propõe a substituição do intangível pela finitude de tais recursos.

\section{MUDANÇA PARADIGMÁTICA NO TRATAMENTO DAS ÁGUAS: DA INFINITUDE À ESCASSEZ}

A água é um recurso inegavelmente ambiental e de caráter essencial às funções vitais. Existe na biosfera na forma líquida (salgada e doce), sólida (doce) e de vapor (doce). A sua forma líquida constitui cerca de 97,72 \% da encontrada na biosfera, sendo 97\% salgada e somente 0,72\% doce (SIRVINSKAS, 2007, pág. 201).

Desde que houve o esfriamento da Terra, há 56 bilhões de anos, permanece a mesma quantidade de água, ou seja, 1,4 bilhão de metros cúbicos (salgada e doce). Somente 90 mil quilômetros cúbicos (doce) encontram-se aptos ao consumo humano, mas nem todo este estoque está disponível na natureza, e só podemos utilizar os recursos renováveis pelas chuvas, reduzindo-se para 34 mil quilômetros cúbicos anuais, correspondendo a $0,002 \%$ das águas do planeta. O aumento do consumo duplicará nos próximos 35 anos, chegando ao limite da disponibilidade da água. Atualmente, perto de 70\% da água do mundo é utilizada para a agricultura (SIRVINSKAS, 2007, págs. 199 e 200).

Além do aspecto da escassez e da má qualidade, a água não é distribuída de forma equânime no planeta. Não bastasse o percentual ínfimo de água doce aproveitável para o consumo humano, sua distribuição ocorre de modo desigual no Planeta Terra, havendo lugares onde os recursos hídricos são abundantes, ao passo que em outros a escassez constitui problema histórico, como no caso do Oriente Médio e dos desertos 
espalhados pelo mundo, como ocorre no caso do Deserto do Atacama no Chile, considerada a região com os índices pluviométricos mais baixos do Planeta.

Averba Vladimir Passos de Freitas (2010, págs. 17/19) que a água, sempre considerada elemento inesgotável, passou a receber tratamento mais atento. Com razão, pois o esgotamento dos recursos naturais no planeta e o aumento populacional levaram o precioso líquido a tornar-se cada vez mais disputado. A água também tem predominado nas discussões referentes às mudanças climáticas globais. Relatórios emitidos pelo IPCC (Painel Intergovernamental de Mudanças Climáticas) as conseqüências do aquecimento global atingirão os recursos hídricos da Terra. Segundo estimativas da FAO (Organização das Nações Unidas para Agricultura e Alimentação) dentro de 20 anos, uma proporção de dois terços da população do mundo deve enfrentar escassez de água. O consumo de água dobrou em relação ao crescimento populacional no último século. O Brasil, nos últimos anos, vem tomando consciência do problema. Afinal, um povo que possui os maiores rios do mundo tem dificuldade em imaginar que pode ficar sem água. Mas, apesar de termos cerca de 13,7\% da água doce disponível no mundo, a verdade é que os problemas vêm se agravando. No Nordeste a falta de água é crônica. No Sudeste é abundante, porém de má qualidade. A invasão das áreas de mananciais hídricos pela população carente é um dos maiores problemas de São Paulo. Os dejetos industriais lançados ao rio Paraíba do Sul tornam precária a água que abastece o Rio de Janeiro e outras cidades. Falta água para irrigar os arrozais do Rio Grande do Sul. A Amazônia, em 2005, enfrentou a pior seca causada por um aquecimento fora do normal nas águas do Atlântico Norte, deixando comunidades sem água e sem alimento.

No Brasil, os anos de 2014 e 2015 foram sintomáticos nos efeitos deletérios da seca. Como exemplo, observou-se no Estado de São Paulo, que concentra a maior economia do País, a crônica falta de água. A principal metrópole brasileira conviveu com vários dias consecutivos de falta de abastecimento de água quando seu principal reservatório - Cantareira - atingiu níveis jamais vistos de escassez, ao utilizar o primeiro e o segundo níveis do Volume Morto (reserva técnica), dificultando a satisfação básica das necessidades humanas mais comezinhas da população afetada. No Estado de Minas Gerais, a nascente do Rio São Francisco (um dos principais do País), secou. A Região Nordeste no ano de 2016 completou o sexto ano consecutivo de estiagem, representando a pior seca nos últimos 50 (cinquenta) anos. Por seu turno, as Regiões Norte e Sul apresentaram o problema inverso, com o registro recorde dos índices pluviométricos. 
Além da escassez, o Brasil também enfrenta problemas como a ausência na manutenção de encanamentos; a falta de conscientização e educação dos usuários na utilização racional e adequada da água; poluição dos rios e a ausência de saneamento básico.

A desigualdade no acesso aos recursos aquíferos também é verificada em outros países. No Equador, de acordo com Alain Dubly (DUBLY, Alain, 2004, p. 89/90) existem áreas desprovidas e outros sobrepostas de recursos aquíferos, anos e estações de seca e outros de alta pluviosidade. Os excessos e faltas ocorrem no espaço e no tempo. Prejudicial para o desenvolvimento normal da vida para os danos que causam: mortes e destruição, epidemias e desnutrição, imobilização ou empurram a migração.

Como agente transformador, atribui-se ao indivíduo o cuidado especial de preservar e manter na propriedade os recursos naturais nela existentes. Como ferimento à sustentabilidade muitos governos implementaram políticas públicas devastadoras e desastrosas em relação à gestão dos recursos hídricos.

No plano das relações internacionais observa-se que um dos principais núcleos temáticos que serve como fonte de ameaças à segurança internacional é a competição por água ou outros recursos naturais essenciais à manutenção da vida humana no Planeta Terra.

Quando se analisa a evolução e amadurecimento da humanidade, verifica-se que os indivíduos quase sempre buscaram adquirir suas propriedades e se instalar em regiões de solo fértil e abundante em água, onde as suas atividades de subsistência (agricultura, pecuária ou extrativismo), desenvolviam-se com mais facilidade. $\mathrm{O}$ aumento populacional e o desenvolvimento econômico impuseram uma necessidade crescente de manejo dos recursos naturais, dentre avulta em importância a água.

Para Maria Luiza Machado Granziera (2006, pág. 63) o equilíbrio entre os possíveis usos da água (ou os usos múltiplos da água) tem sido considerado o ideal, observados, também, os aspectos sociais e ambientais envolvidos, além da questão econômica. Essa recomendação ilustra a tendência moderna de se procurar um equilíbrio entre as diversas utilizações dos recursos hídricos, de forma que se obtenham resultados não só técnicos, mas também sociais.

\section{O RECONHECIMENTO DO ACESSO À ÁGUA COMO DIREITO HUMANO}

O acesso à água é hoje visto como um direito humano, a partir da constatação de sua essencialidade para a manutenção da vida no planeta. Neste sentido, 
foram editadas várias Convenções, Acordos e Tratados Internacionais que versam sobre a proteção da água e estabelecem bases para que os países signatários criem um sistema próprio de gerenciamento dos recursos hídricos, de forma a propiciar o seu uso racional.

Como corolário desta nova ordem no plano internacional, podem ser mencionadas as conferências mundiais, tais como: Estocolmo (1972), Brundlant (1987), Madrid (1991), Rio de Janeiro(1992) - Cúpula da Terra, Paris, 1991 - Ya Wananchi, Conferência Global de Organizações Não-Governamentais, Johanesburgo, 2002, e outras que apontam para inúmeras medidas ambientais urgentes a serem tomadas e grandes preocupações, tanto dos países de primeiro mundo como os periféricos, a respeito dos abusos, uso, comercialização, incorporações, da escassez e da grande devastação associada à poluição da água.

A Declaração de Estocolmo, elaborada durante a Conferência de 1972, destaca, em seu Princípio 21, que os Estados possuem direito à exploração dos recursos naturais situados em seus territórios, determinando, contudo, que tal exploração se dê de forma a não causar danos ambientais a outros Estados. Os documentos internacionais que se sucederam igualmente trataram das formas de encontrar a utilização sustentável dos recursos hídricos, destacando-se o desafio de aliar a soberania estatal sobre os recursos naturais e a busca pela exploração não prejudicial aos países, desafio este que se estende aos planos de gerenciamento dos recursos hídricos, englobando o aspecto atinente à utilização das águas transnacionais.

Em 1992 durante a Conferência Internacional sobre Água e Meio Ambiente, consagrou-se a Declaração de Dublin que, em seu Art. $1^{\circ}$ - reconheceu que a água é um recurso finito e vulnerável, essencial para a manutenção da vida, do desenvolvimento e do meio ambiente; partindo-se do princípio que a água sustenta a vida, a gestão dos recursos hídricos requer uma abordagem holística, integrando o desenvolvimento econômico e social com a proteção dos ecossistemas naturais. A sua gestão efetiva integra o uso do solo com os usos da água no âmbito da bacia de drenagem ou do aquífero subterrâneo. Os -Princípios de Dublin\| norteiam a gestão e as políticas públicas para as águas em todo o Planeta.

A Conferência Internacional sobre Água e Desenvolvimento Sustentável, realizada em Paris, em 1.998, constatou que 1/4 da população mundial não tem acesso à água potável, mais de $50 \%$ da população mundial carece de saneamento básico (esgoto) e a baixa qualidade da água e a falta de higiene figuram entre as causas de enfermidades e morte. Calcula-se que $33 \%$ dos óbitos são causados por problemas atinentes à 
qualidade dos recursos hídricos, nos países em desenvolvimento. Assim a água é o bem mais importante para o homem continuar vivendo neste planeta (SIRVINSKAS, 2007, pág. 201).

Em Julho de 2010, por proposição da Bolívia (país que apresenta um histórico de luta da população contra o processo de privatização de seus serviços de água e saneamento), com resolução favorável de centenas de países, inclusive o Brasil, o acesso à água potável e ao saneamento básico foi declarado pela Assembléia Geral da Organização das Nações Unidas (ONU) como um direito humano essencial, fato este que denota a preocupação com a situação de milhões de pessoas em todo o mundo sem acesso a fontes de água limpa, submetidas às mais diversas agruras daí decorrentes. $\mathrm{O}$ reconhecimento da água como direito humano decorre do seu caráter essencial para o pleno gozo de uma vida humana com dignidade.

A água encontra-se na encruzilhada entre seu enquadramento como bem econômico e como direito humano. Conforme o diagnóstico de Vladimir Passos de Freitas (2010, págs. 24 e 25) a privatização da água foi um assunto muito discutido no IV Fórum Mundial da Água, que aconteceu em 2006, na Cidade do México. Os participantes do evento e membros de ONGs internacionais criticaram a participação das empresas e instituições financeiras no Fórum, alegando que a discussão sobre a água concentrouse somente na visão empresarial e não, como um direito humano fundamental. Também fizeram manifestações deixando clara a não-aceitação da privatização da água já que esta é um direito e não, uma mercadoria. A preocupação maior vem com o abastecimento das populações carentes. Teme-se que a privatização possa resultar na negativa desse bem, indispensável para a sobrevivência.

Para Samuel Pinheiro Guimarães (2007, págs. 83 e 84) a deterioração do meio ambiente e a crescente escassez de recursos naturais, em especial a água, e, em breve, o petróleo, levam à convicção de que é impossível reproduzir nos países da periferia os atuais padrões de consumo dos países do centro. Essa convicção está por trás da ideologia do -desenvolvimento sustentável\| que, em primeiro lugar, desvia a atenção da opinião pública da necessidade e da obrigação dos países centrais de reduzirem seus padrões de consumo, marcados pelo desperdício de recursos e a poluição.

Em 2012, foi promovida no Rio de Janeiro a Conferência das Nações Unidas sobre Desenvolvimento Sustentável (CNUDS), também denominada de -Rio $+20 \|$, considerada um dos maiores eventos realizados pelas Nações Unidas na temática ambiental. Ao seu término houve a publicação do documento "O Futuro que 
Queremos", que tratou expressamente de questões relacionadas à água. Vários assuntos sobre ela foram abordados, como a importância do saneamento básico em sua gestão, a governança hídrica, dentre outros, mas aquele que ganhou maior destaque foi o direito humano à água. Convém salientar que o processo para a inclusão do direito humano de acesso à água e ao saneamento básico na declaração final não foi fácil. Correu-se o risco dele não constar nela, pois na sua minuta, esboço do documento realizado antes da conferência, ele não estava presente. A partir das pressões sofridas, inclusive pelos movimentos sociais durante a Rio+20, foi assumido o compromisso pelos Estados no cumprimento da Resolução da ONU 64/292, aprovada no dia 28 de julho de 2010, o que acabou acontecendo, sendo acrescentados os itens 119 a 124 sobre o tema na Declaração Final da Conferência das Nações Unidas sobre Desenvolvimento Sustentável (RIO + 20). Foi nesse evento, em razão dessa mobilização, que se declarou o dia 28 de julho como o Dia Internacional da Luta Pelo Direito à Água.

De acordo com Maria de Fátima Schumacher Wolkmer e Milena Petters Melo (2013, pág. 21) o direito humano à água é uma conquista muito recente da comunidade internacional. Este reconhecimento extraordinário pode ser compreendido dentro da evolução normativa dos direitos humanos como proteção da dignidade da pessoa humana e da vida nas suas múltiplas dimensões. No sistema internacional de proteção dos direitos humanos, abrangência do direito a uma vida digna pressupõe a possibilidade real de satisfazer uma série de necessidades socioeconômicas e os Estados devem garantir o acesso igual de todos a fatores determinantes da saúde como alimentos nutritivos, água potável, condições sanitárias adequadas, habitação, condições de trabalho seguras, um meio ambiente saudável e acesso à educação básica etc. Trata-se de garantir o direito à vida não só como garantia contra sua privação ilegal, senão como o direito de acesso àqueles bens e serviços, imprescindíveis para sua conservação e a água é sem dúvida o elemento mais importante.

No sistema capitalista, para além de bem ambiental a água passou a ostentar um crescente valor econômico, encontrando-se presente em todos os bens de consumo produzidos pela agricultura e pelas indústrias, de forma direta ou virtual. O aumento da população mundial acarretou vários problemas, o desmatamento, as mudanças climáticas e o uso indiscriminado dos recursos naturais levaram vários países a sofrer com a escassez de água, o acesso à água limpa para o consumo foi reconhecido como um direito humano universal. A legislação brasileira vem evoluindo para proteger esses recursos, mas ainda apresenta muitas falhas, podendo-se citar como exemplo a ausência 
de efetiva proteção e fiscalização no uso e exploração de águas subterrâneas. O aprofundamento da escassez da água revela a necessidade de cuidado com os recursos aquíferos como elemento vetorial da dignidade de um direito universal.

A água é o elemento vital e primordial para a sobrevivência não apenas da vida humana, mas, adotando-se uma perspectiva sócio-biocêntrica, de todas as manifestações de vida no Planeta Terra.

No tocante à visão antropocêntrica das águas preleciona Alicia Granda (2004, p. 106), para a maioria da humanidade a água é considerada um recurso hídrico, ou seja, do ponto de vista da sua extração, sem considerar os ciclos naturais e as condições exigidas ou benefícios biológicos promove para a conservação dos ecossistemas. Esta visão antropocêntrica equivocada inclui relações dos grupos humanos com a água. Assim se explica, em alguma medida, a prioridade que os setores envolvidos outorgam ao aspecto técnico da utilização e distribuição de água, e a tendência à apropriação e privatização da água. É preciso abordar a ideia de que a água é um bem natural com as quais compartilhamos e, portanto, seu uso tem limites.

No caso brasileiro, observa-se que a abundância aquífera gerava uma situação de despreocupação dos cidadãos com a educação ambiental na gestão dos recursos hídricos. Em 2014, com a escassez do recurso ante a ocorrência de seca nas Regiões Sudeste e Nordeste, causou grande impacto no relacionamento dos usuários, em especial criando práticas de respeito na utilização racional da água potável, notadamente nas duas maiores metrópoles do País (São Paulo e Rio de Janeiro) que foram seriamente impactadas pela carência hídrica. Nesse mesmo ano instalou-se um conflito federativo entre os Estados de São Paulo e Rio de Janeiro, envolvendo também a ANA (Agência Nacional de Águas) e os comitês das bacias, com a proposta paulista de transposição das águas da Bacia Paraíba do Sul para o Sistema Cantareira, esta crise suscitou uma série de questionamentos acerca da segurança hídrica das populações abastecidas pelos rios Paraíba do Sul e Guandu.

De acordo com o Programa das Nações Unidas para o Meio Ambiente (PNUMA), no GEO5, Panorama Ambiental Global (PNUMA, 2012, p. 06) as pressões humanas sobre o sistema terrestre aceleram, diversos limiares críticos globais, regionais e locais estão próximos de serem ultrapassados, ou até já o foram. Uma vez ultrapassados, é provável que ocorram mudanças climáticas abruptas e possivelmente irreversíveis às funções que sustentam a vida do planeta, com implicações adversas significativas para o bem-estar humano. 
Para o Programa das Nações Unidas para o Meio Ambiente (PNUMA), no GEO5, Panorama Ambiental Global (PNUMA, 2012, p. 06), o Planeta está a caminho de cumprir o Objetivo de Desenvolvimento do Milênio de acesso à água, mas não o de acesso ao saneamento — 2,6 bilhões de pessoas ainda não têm acesso a saneamento básico —, e houve algum progresso no alcance das metas de eficiência hídrica. Apesar do progresso, há preocupações de que o limite da sustentabilidade dos recursos hídricos, tanto das águas de superfície como das subterrâneas, já tenha sido alcançado ou até ultrapassado em muitas regiões; de que a demanda por água continua a aumentar; e de que o estresse relativo à água por parte das pessoas e da biodiversidade intensifica-se rapidamente. A extração mundial de água triplicou nos últimos 50 anos; os aquíferos, bacias e áreas úmidas estão cada vez mais ameaçados, mas mesmo assim são mal manejados e monitorados. O ritmo da redução dos estoques globais de águas subterrâneas mais do que dobrou entre 1960 e 2000. Hoje, 80 \% da população mundial vive em áreas com graves ameaças à segurança hídrica, sendo que a mais grave categoria de ameaça afeta 3,4 bilhões de pessoas, quase todas nos países em desenvolvimento. Até 2015, havia a previsão que 800 milhões de pessoas ainda não teriam acesso a um melhor abastecimento de água, embora melhorar o abastecimento de água e o saneamento ainda é uma maneira de baixo custo de reduzir as doenças e mortalidade relacionadas à água. Em muitos países, não há coleta de dados, monitoramento e avaliação da hidrologia, da disponibilidade de água e da qualidade da água, essenciais para o manejo integrado dos recursos hídricos e o desenvolvimento

sustentável.

De acordo com Alain Dubly (2004, p. 83) um bilhão de pessoas (18\% da população mundial) não têm ainda acesso à água de boa qualidade. As doenças relacionadas com a água causas a morte de 3,5 milhões de pessoas a cada ano, na maioria crianças.

Para Oscar López Goldaracena (2004, p. 16) em particular relacionada ao acesso à água potável e saneamento, são conhecidos, que são pré-requisitos para a realização do direito de padrão de vida adequado ou uma vida com dignidade, em seu mérito, fortalecem seu fundamento jurídico para ser considerados direitos humanos. Não há dúvida de que eles estão intimamente ligados ao exercício de outros direitos fundamentais: o direito à saúde, direito à moradia, direito à alimentação etc.

De acordo com Matheus Gazzola Tussi (2008, pág. 88) as águas subterrâneas sempre desempenharam um importante papel para a humanidade, mas por muito tempo 
a capacidade de extrair a água do subsolo foi muito pequena em relação à quantidade armazenada. Com o avanço no conhecimento, as melhoras tecnológicas fizeram com que houvesse uma grande extração a partir da década de 1950. Na contemporaneidade, a extensão dos aquíferos é relativamente bem conhecida na maior parte do mundo, como resultado da melhora no mapeamento geológico e na interpretação hidrogeológica nos últimos 10 a 30 anos. Estima-se que, globalmente, as águas subterrâneas sejam responsáveis por $50 \%$ do suprimento de água potável, $40 \%$ da água utilizada na indústria e $20 \%$ da água que se utiliza para a irrigação na agricultura.

A utilização indiscriminada, irresponsável e perene dos recursos hídricos coloca em risco a sobrevivência da humanidade. No Brasil é diuturna a prática de perfuração de poços artesianos independentemente do conhecimento, autorização e fiscalização do poder público, sem a devida contraprestação pecuniária, causando sérios prejuízos para a coletividade e para as gerações vindouras uma vez que muitas vezes ocasiona a poluição dos lençóis freáticos acarretando em consequências irreparáveis ao meio ambiente.

O paradigma atual revela a limitação e o caráter finito dos recursos hídricos, aliado à degradação de sua qualidade. Seu elevado nível de escassez resultou na necessidade de reconhecer o seu valor econômico, social e o ambiental. A água deixou, então, de ser considerada res nullius, passando a ser res communis (bem de uso comum do povo). A patrimonialização da água ecoou em diferentes ordenamentos internacional (documentos emanados da ONU e da OMS), regional (União Europeia e UNASUL) e nacional (Brasil, Bolívia, Equador, França...) - e fez emergir o regime jurídico dos recursos hídricos, no Brasil, implementado pela Lei de Política Nacional de Recursos Hídricos, a Lei Federal nº 9.433/1997.

Ao dissertar acerca da água como um bem de valor econômico aduz Paulo Affonso Leme Machado (2002, pág. 32 )que a água é um recurso natural limitado, e não ilimitado, como se raciocinou anteriormente no mundo e no Brasil. A água passa a ser mensurada dentro dos valores da economia. Isso não pode e não deve levar a condutas que permitam que alguém, através do pagamento de um preço, possa usar a água a seu belprazer. A valorização econômica da água deve levar em conta o preço da conservação, da recuperação e da melhor distribuição desse bem.

Ao tratar da água como bem econômico e dos modelos de privatização para águas e esgotos preleciona Vladimir Passos de Freitas (2010, pág. 24) que pouco se 
sabe no Brasil sobre tal espécie de privatização, mas que ela já vem sendo feita no Chile e na Argentina.

A Emenda Constitucional No.: 64/2010 inseriu o direito social à alimentação no rol do art. 6- da Carta Política de 1988. Trata-se de inclusão intrinsecamente concatenada ao reconhecimento do direito humano à água potável, uma vez que sua ausência implica em desequilíbrios alimentares e fomes endêmicas. Em 2014 a Comissão de Constituição e Justiça e de Cidadania da Câmara dos Deputados aprovou, a admissibilidade da Proposta de Emenda à Constituição (PEC) n ${ }^{\circ}$ 39/07 que inclui a água no rol dos direitos fundamentais sociais do Art. $6^{\circ}-$ da CF/88. No plano prospectivo, o reconhecimento da água como um direito humano fundamental implica na situação consoante a qual o Estado poderá ser responsabilizado pelo seu provimento para toda a população, superando-se a visão puramente econômica dos recursos hídricos.

A partir da constatação de que a maioria da população mundial vive em grandes metrópoles, eis que surge um problema fundamental e carecedor de soluções : a falta de acesso à água potável. O encarecimento na prestação dos serviços públicos de acesso à água e ao saneamento gerou a exclusão de parcela significativa da população, o que torna tais indivíduos em vítimas de marginalização ou discriminação. O seu acesso insatisfatório à água e saneamento é um dos elementos de perpetuação na sua situação de pobreza.

Para Antonio Enrique de Perez Luño (2007, p. 46) os direitos humanos são compreendidos como um conjunto de faculdades e instituições que, em cada momento histórico, materializam as exigências da dignidade, da liberdade e da igualdade humanas, as quais devem ser reconhecidas positivamente pelos ordenamentos jurídicos nos níveis nacional e internacional.

Por seu turno Gregorio Robles (1997, p. 19/20) ensina que os "direitos humanos" ou "direitos do homem", classicamente chamado de "direitos naturais" e na atualidade de "direitos morais", não são, em verdade, autênticos direitos- protegidos por ação judicial perante um juiz -, mas especialmente relevante critérios morais para a sociedade humana. Uma vez que os direitos humanos, ou melhor, certos direitos humanos, tornam-se positivos, adquirindo categoria real de direitos processualmente protegidos, eles se tornam "direitos fundamentais" de um determinado ordenamento jurídico. 
Neste jaez tal reconhecimento materializa o enquadramento do acesso humano à água potável e ao saneamento básico na perspectiva dos direitos humanos, consoante esposado pela Declaração Universal dos Direitos do Homem e do Cidadão proclamada pela Assembleia Geral das Nações Unidas em 1948. A partir de sua incorporação em alguns textos constitucionais (exemplo Constituição do Equador de 2008) torna-se também um direito fundamental.

Conforme esposado por Joaquín Herrera Flores (2009, pág. 36), começamos a lutar pelos direitos, porque consideramos injustos e desiguais tais processos de divisão do fazer humano. Para tanto, todos precisamos dispor de condições materiais - e imateriais - concretas que permitam o acesso aos bens necessários para a existência.

Verifica-se que as pessoas que vivem em situação de pobreza pagam frequentemente um preço mais elevado por serviços essenciais, aí incluídos a água e o saneamento. Sem ligações legais à rede formal de água e saneamento, tais indivíduos adquirem informalmente água de qualidade duvidosa.

Uma das diretrizes do reconhecimento dos direitos humanos à água e ao saneamento perpassa necessariamente pelo reconhecimento de que tais serviços públicos qualifiquem-se como essenciais, bem como enquadrem-se em critérios aceitáveis, seguros e acessíveis física e economicamente para todos quando de seu fornecimento aos usuários.

Um dos corolários que ora se propõe é o reconhecimento e valorização dos países na adoção de medidas imediatas que têm por escopo o término das violações dos direitos humanos atinentes à água potável e ao saneamento básico para que todas as pessoas venham a gozar de uma vida com dignidade.

Na busca de superação deste dilema, eis que em Julho de 2010, o acesso à água potável e ao saneamento básico foi declarado pela Assembleia Geral da Organização das Nações Unidas (ONU) como um direito humano essencial.

Preleciona Joaquín Herrera Flores (2009, pág. 39) que o conteúdo básico dos direitos humanos será o conjunto de lutas pela dignidade, cujos resultados, deverão ser garantidos por normas jurídicas, por políticas públicas e por uma economia aberta às exigências da dignidade.

\section{A ÁGUA COMO DIREITO DA NATUREZA: ELEMENTO INFORMATIVO DO NOVO CONSTITUCIONALISMO DEMOCRÁTICO LATINO-AMERICANO}


Indubitavelmente, muitos dos conflitos internacionais que ameaçam a paz têm origem na disputa por recursos naturais, dentre os quais avulta de importância o acesso à água.

A ocorrência de profundos desequilíbrios ambientais planetários, tais como o esgotamento do solo, as queimadas e desmatamentos, a mortandade da fauna e da flora, a poluição e escassez da água, o aquecimento global e outras alterações climáticas de um modo geral, foram causadas por ações naturais, mas, principalmente por influência direta do próprio ser humano, que em busca do crescimento econômico acelerado a qualquer custo e ao consumismo irracional, acabou utilizando de maneira desmedida e desregrada os recursos naturais da Mãe Terra, causando uma enorme desestabilização na ordem ecológica. Esses problemas afetam direta e indiretamente a qualidade de vida, não só do ser humano, mas de todas as espécies, sendo que muitas delas estão em extinção ou já foram dizimadas.

O conflito popular ocorrido em território boliviano foi a Guerra da Água em 2000 contra a privatização dos serviços de água na cidade de Cochabamba. O resultado desse processo foi uma reorganização dos movimentos sociais e a ascensão ao poder de partidos afinados com diversos segmentos sociais tradicionalmente excluídos da participação política proativa, como se deu em relação aos indígenas, campesinos, mulheres e algumas categorias de trabalhadores.

Esses processos reivindicatórios acarretaram em conquistas constitucionais em países plasmadas nas Constituições do Equador (2008) e da Bolívia (2009) mediante a atuação dos grupos sociais emergentes (indígenas, negros, mulheres e outros) na construção do Novo Constitucionalismo Democrático Latino-Americano. Eis que o movimento recebeu a alcunha de um -constitucionalismo sem paisll, rompendo, portanto com a carga histórica da opressão que marcou o constitucionalismo sulamericano, buscando afastar-se dos interesses particulares e elitistas.

De acordo com Roberto Viciano Pastor e Rubén Martínez Dalmau (2010, pág. 22) o Novo Constitucionalismo Democrático Latino-Americano, que tem sido descrito como -constitucionalismo sin padres", difere do constitucionalismo anterior no campo da legitimidade, pela natureza dos conjuntos constitutivos.

No modelo tradicional de constitucionalismo a construção política do Estado e de seus aparatos jurídicos, compunha um privilégio das classes economicamente dominantes que impunha suas diretrizes ao povo. O Novo Constitucionalismo Demorático Latino-Americano busca a inversão do percurso comum, e brota do seio 
popular; a constituição deixa de nascer no âmbito exclusivista das minorias hegemônicas para atender ao chamado dos plurais anseios e clamores populares, em especial dos povos autóctones ameríndios na consagração dos direitos da natureza.

Na análise de Boaventura de Sousa Santos (2012, pág. 13) no final da última década, Bolívia e Equador foram os dois países latino-americanos que passaram por transformações constitucionais mais profundas no curso de mobilizações políticas protagonizadas pelos movimentos indígenas e por outros movimentos e organizações sociais e populares. Não é de estranhar, portanto, que as constituições de ambos os países contenham embriões para uma transformação paradigmática do direito e do Estado moderno, sendo legítimo falar de um processo político de refundação, social, econômico e cultural.

Neste jaez assevera Germana de Oliveira Moraes (2013, pág. 128) que na confluência do dilema entre os direitos de Pachamama (da natureza) e os direitos humanos, e, perante este grande desafio de nosso tempo de articular e compatibilizar as macropolíticas ambientais, exigências do mandato ecológico, introduzindo na Constituição Equatoriana, de maior preservação dos ecossistemas, com as macropolíticas sociais minimizadoras das desigualdades sociais e regionais, sobretudo nos países menos desenvolvidos do Hemisfério Sul, o modelo Bem Viver, ora em construção, parte da crença que não seja possível equacionar essas questões sem que se reveja a relação do ser humano com as forças cósmicas e telúricas, simbolizadas, respectivamente, pelo Pai Sol e pela Mãe Terra (Pachamama), pautando-se fundamentalmente no valor da harmonia, desdobrável em variáveis como, por exemplo, unidade, inclusão, solidariedade, reciprocidade, respeito, complementaridade e equilíbrio.

Uma das formas de utilização da água que mais agridem a sua caracterização como direito da natureza é a poluição hídrica, gerando efeitos deletérios para a humanidade, tanto em relação às gerações presentes como as vindouras.

Para Maria de Fátima Schumacher Wolkmer e Milena Petters Melo (2013, pág. 22) no marco do Novo Constitucionalismo Democrático Latino-Americano e da cosmovisão andina, a questão da fruição do direito fundamental à água cresce em complexidade e implica enfrentar de modo original, enormes desafios, que seguem no sentido da promoção de um modelo de Estado de Bem Viver, assentado na cidadania plural, que assume o controle estratégico dos recursos hídricos, garantindo a água para todos os setores da sociedade e para a manutenção dos ciclos vitais da natureza. 
A poluição hídrica é a degradação da qualidade ambiental resultante de atividade que direta ou indiretamente lance matérias ou energia nas águas em desacordo com os padrões ambientais estabelecidos. Revela-se na alteração dos elementos constitutivos da água (hidrogênio e oxigênio), tornando-a imprópria ao consumo ou à utilização para outros fins. A descarga de esgoto doméstico e de efluente industrial sem tratamento e a disposição de resíduos sólidos nos cursos d’água e nos mananciais vem comprometendo, cada vez mais, a qualidade dos recursos hídricos, dificultando e acarretando custos crescentes para atender aos objetivos do fornecimento de água de boa qualidade (SIRVINSKAS, 2007, pág. 201).

Para Antônio Carlos Wolkmer, Sérgio Augustin e Maria de Fátima S. Wolkmer (2012, págs. 53 e 54) trabalhar por uma nova cultura, ainda que tenha em conta os parâmetros convencionais do Estado, Mercado e Sociedade Civil, implica em ir mais além, incorporando a natureza e sua preservação como bem mais precioso. Uma nova cultura que harmonize a Vida Humana com a natureza, compartilhando princípios, estratégias e -novos\| Direitos. Nessa nova cultura orientada para o - bem viverl, é essencial e irrenunciável um —novo Direito, o Direito Humano aos bens enquanto patrimônio comum. Ora, no cenário mundial, a ONU reconheceu, em 28/07/2010, a água potável e o saneamento básico como um Direito Humano fundamental, em duas históricas Resoluções. Em tal horizonte, complexo e fundamental, a questão dos recursos naturais como patrimônio comum na América Latina compreende um gerenciamento ambiental não tecnocrático (via estatismo ou ordem privada), mas comunitário, participativo e plural. A proposta, aqui, é trazer para a pauta e destacar o desafio ético da importância dos recursos naturais (como a água) enquanto —novo Direito, um Direito Humano construído não mais de - cima para baixo, mas por estratégias — desde baixo, ou seja, desde a comunidade em sintonia com a sustentabilidade da natureza. Na verdade, trata-se de uma ruptura paradigmática, de projetar uma nova cosmovisão. Essa cosmovisão contra-hegemônica vem sendo projetada em nível teórico e em nível prático pelas experiências recentes da cultura social, política e jurídica dos Andes Latino-Americanos, mais especificamente pelos modelos desenhados e oficializados nos Estados da América Latina, dentre os quais, Equador e Bolívia.

Na visão de Aniza García (2008, p. 184/185) o acesso à água é um componente essencial na luta para a erradicação da pobreza e é necessária para a plena eficácia da condição conjunto de direitos, é agora constitui uma verdade evidente; no entanto, o 
desafio de garantir o acesso a cada indivíduo e da comunidade à água potável e ao saneamento adequado como um verdadeiro direito humano requer um compromisso firme de todas as partes interessadas, e em especial os poderes público e privado. Porque se é verdade que a atual crise de água levou à conclusão de inúmeros fóruns internacionais com vista a encontrar possíveis soluções para a escassez global e distribuição de água, e promover uma gestão integrada e ambientalmente sustentável dos recursos, infelizmente, alguns dos mais poderosos setores políticos e econômicos em nível mundial aproveitaram esta conjuntura para impor um modelo de gestão que é para o benefício exclusivo dos seus interesses.

O novo modelo de gestão dos recursos hídricos institucionalizado pela Constituição Boliviana de 2009, funda-se na possibilidade de alteração de velhos paradigmas para a preparação da sociedade fundada nos grandes impasses do século XXI, , como forma de inclusão de todos os cidadãos, com o escopo de atender ao direito social à alimentação, fruto do Constitucionalismo Andino Transformador fundado na cosmovisão indígena.

Como consectário tem-se a lição de Fernando Huanacuni Mamani (2010, p. 85) consoante a qual na visão dos povos indígenas, a Mãe Água é sagrada. Neste sentido, na atualidade, a água, é ser vista como um elemento susceptível de ser comercializada, que está gerando grande preocupação entre os povos nativos.

Conforme averbado por Hans Jonas (1995, págs. 304) a punição infligida à natureza com a maximização de técnicas agrícolas já começam a mostrar sinais de seus progressivos efeitos desastrosos, por exemplo, a poluição química das águas interiores e costeiras (para que a indústria presta sua própria contribuição) na cadeia de ação sobre os organismos. Salinização do solo devido à irrigação constante, erosão da terra devido às alterações de compensação, o clima (talvez até mesmo a diminuição de oxigênio na atmosfera), devido ao desmatamento são conseqüências de uma agricultura cada vez mais intensiva e estendida.

Aduz Christian Guy Caubet (2008, pág. 19) que enquanto a Organização das Nações Unidas para a Alimentação e a Agricultura (FAO) já declarou ser necessário colocar à disposição de cada ser humano 40 litros de água potável por dia, no lugar onde vive a pessoa, no planeta Terra 1,1 bilhão de seres humanos vivem sem água potável, e 2,4 bilhões não têm acesso a instalações sanitárias. Trinta e quatro por cento da população de cidades como México, Karachi, Manila, Rio de Janeiro, Buenos Aires, Casablanca, dentre outras, não têm acesso direto à água potável. 
Segundo afirma Esperanza Martínez (2010, p. 335/336) para os povos indígenas e para as populações que mantêm uma ligação com a natureza, a água é sagrada, e o sagrado é uma forma de expressar a humildade ante as forças que não conseguimos entender. A defesa da água é uma questão central na agenda dos povos indígenas, seja por manter o acesso à água, para manter o controle de seus territórios ou para evitar operações industriais, como a exploração de mineração ou petróleo, que causam poluição fontes de água, destruição de ecossistemas e que utilizam grandes quantidades de água.

Neste sentido, merece menção o art. 12 da Constituição do Equador de 2008 ao dispor que o direito humano à água é fundamental e irrenunciável, determinando ainda que a água constitui patrimônio nacional estratégico de uso público, inalienável, imprescritível e essencial para a vida.

Para Alberto Acosta (2010, p. 20), no processo constituinte equatoriano, para a formulação das bases do tratamento jurídico das águas, as discussões centraramse, principalmente, em quatro premissas: 1. A água é um direito humano; 2. A água é um bem nacional estratégico de uso público; 3. A água é um patrimônio da sociedade; 4. A água é um componente fundamental da natureza, a mesma que tem direitos próprios a existir e manter seus ciclos vitais.

\section{CONSIDERAÇÕES FINAIS}

A água constitui-se na base de todos os direitos humanos fundamentais, porque é essencial à dignidade da pessoa humana e ao estabelecimento de uma vida saudável e sem esta não há que se cogitar a existência dos seres vivos no Planeta Terra na satisfação de seus direitos básicos de alimentação e saúde. A problemática ambiental do mundo moderno não pode prescindir da necessidade de uma eficaz gestão dos recursos hídricos a fim de evitar-se o problema cada vez mais premente da escassez dos recursos hídricos.

O escopo do reconhecimento do direito humano à água é evitar-se que os erros cometidos no passado não venham a repetir-se e seus efeitos deletérios não venham a repercutir negativamente para as gerações vindouras. Neste jaez, em 2010 a Organização das Nações Unidas (ONU) declarou o acesso à água potável e ao saneamento básico como direito humano. Partiu de proposta da Bolívia, que já se encontrava positivada na Constituição do Equador (2008), como corolário do Novo Constitucionalismo em fase de construção nos países da América Latina. 
A necessidade premente de normatização dos recursos hídricos nos planos nacionais e internacionais é decorrência do seu reconhecimento como direito humano, bem como de seus usos múltiplos hodiernamente em relação a toda a conjuntura mundial, desde a utilização pelos homens para diversos fins (consumo pessoal), passando pelo seu uso na irrigação de culturas agrícolas, pela utilização como meio de transporte, até a sua utilização como fonte geradora de energia para a população dos países. Observa-se que o direito humano à água, em sua definição, ainda precisa ser melhorado uma vez que possibilita a privatização dos sistemas de prestação de serviços hídricos. Nesse sentido, o avanço no tratamento jurídico das águas é representado pela visão consagrada pelo Novo Constitucionalismo Democrático Latino-Americano plasmado pelas Constituições do Equador (2008) e da Bolívia (2009) que consideram a água como fonte de todas as formas de vida, sem possibilidade de privatização de seu domínio, uso e prestação de serviços a ela relativos.

\section{REFERÊNCIAS}

ACOSTA, Alberto. El agua, un derecho humano fundamental. In ACOSTA, Alberto; MARTÍNEZ, Esperanza (compiladores). Agua. Un derecho humano fundamental. Quito-Ecuador: Ediciones Abya-Yala, 2010.

CAUBET, Christian Guy. A água, a lei, a política... e o meio ambiente? $1^{\mathrm{a}}$ - edição. $8^{\mathrm{a}}$ tiragem. Curitiba, 2008.

CAUBET, Christian Guy. O aquífero Guarani e seus sistemas jurídicos: normas e princípios ou laissez faire para as águas subterrâneas?IN MENEZES, Wagner (organizador). Estudos de Direito Internacional: anais do $8^{\circ}$ - Congresso Brasileiro de Direito Internacional. Curitiba: Juruá, 2010.

DUBLY, Alain. Gestión y conflictos. In: DUBLY, Alicia Granda Alain; BORJA, Germania (org.). Agua, vida y conflito. Panorama social del agua em el Ecuador. Quito: Corporación Editora Nacional, 2004.

FIORILLO, Celso Antônio Pacheco. Curso de Direito Ambiental Brasileiro. $8^{\text {a }}$. Edição. São Paulo: Saraiva, 2007. 
FLORES, Joaquín Herrera. A (re)invenção dos direitos humanos. Tradução: Carlos Roberto Diogo Garcia et. all. Florianópolis: Fundação Boiteux, 2009.

FREITAS, Vladimir Passos de. Águas: aspectos jurídicos e ambientais. 3a- edição. Curitiba: Juruá, 2010.

GARCÍA, Aniza. El derecho humano al agua. Madrid: Editorial Trotta, 2008, p. $184 / 185$.

GOLDARACENA, Oscar López. Los derechos humanos al água y saneamiento. Reflexión jurídica desde el Derecho Internacional. Pautas para su cumplimiento. Montevideo, Uruguay, 2004.

GRANDA, Alicia. Los conflitos por el agua. In: DUBLY, Alicia Granda Alain; BORJA, Germania (org.). Agua, vida y conflito. Panorama social del agua em el Ecuador. Quito: Corporación Editora Nacional, 2004.

GRANZIERA, Maria Luiza Machado. Direito das águas: disciplina jurídica das águas doces. $3^{\text {a }}$ - edição. São Paulo: Atlas, 2006.

GUIMARÃES, Samuel Pinheiro. Quinhentos anos de periferia: uma contribuição ao estudo da política internacional. 5 $5^{\text {a }}$ edição. Rio de Janeiro: Contraponto, 2007.

JONAS, Hans. El principio de responsabilidad. Ensayo de uma ética para la civilización tecnológica. Traducción: Javier Ma- Fernández Retenaga. $1^{\text {a }}$ - edición. $3^{\text {a }}$ impresión. Barcelona: Herder Editorial, 1995.

MACHADO, Paulo Affonso Leme. Recursos hídricos: direito brasileiro e internacional. São Paulo: Malheiros, 2002.

MAMANI, Fernando Huanacuni. Vivir bien/Buen vivir. Filosofía, políticas, estratégias y experiências regionales. 4a- edición. La Paz, Bolivia, 2010.

MARTÍNEZ, Esperanza. El Agua limpia y libre es água bendita. El água en el centro de los conflictos ambientales em Ecuador In ACOSTA, Alberto; MARTÍNEZ, Esperanza (compiladores). Agua. Un derecho humano fundamental. Quito-Ecuador: Ediciones Abya-Yala, 2010. 
MORAES, Germana de Oliveira. O constitucionalismo ecocêntrico na América Latina, o Bem Viver e a nova visão das águas. Revista da Faculdade de Direito/Universidade Federal do Ceará. Volume 34, No.: 01 (Janeiro/Junho 2013). Fortaleza: Universidade Federal do Ceará, 2013.

PÉREZ LUÑO, Antonio Enrique. Los derechos fundamentales. Novena Edición. Madrid: Tecnos, 2007.

Programa das Nações Unidas para o Meio Ambiente (PNUMA), no GEO5. Panorama Ambiental Global. Tradução: Cláudia Vargas. Nairóbi, Quênia: 2012.

ROBLES, Gregorio. Los derechos fundamentales y la ética em la sociedad actual. Reimpresión Revisada. Madrid: Editorial Civitas, S.A., 1997.

SANTOS, Boaventura de Sousa. Cuando los excluidos tienen Derecho: justicia indígena, plurinacionalidad e interculturalidad. In: SANTOS, Boaventura de Sousa;

Rodríguez, José Luis Exeni (Editores). Justicia indígena, plurinacionalidad e interculturalidad en Bolivia. Quito: Ediciones Abya Yala, 2012.

SIRVINSKAS, Luís Paulo. Manual de Direito Ambiental. 5a. Edição. São Paulo: Saraiva, 2007.

TUSSI, Matheus Gazzola. Cooperação Internacional e Recursos Hídricos: a formação de um regime internacional para o Aquífero Guarani. Dissertação (Mestrado em Ciências Sociais). Programa de Pós-Graduação em Ciências Sociais, Pontifícia Universidade Católica do Rio Grande do Sul (PUC-RS), Porto Alegre, 2008.

VICIANO PASTOR, Roberto y MARTÍNEZ DALMAU, Rubén. Aspectos generales del Nuevo constitucionalismo latinoamericano. Quito: Corte Constitucional del Ecuador, 2010.

WOLKMER, Antônio Carlos; AUGUSTIN, Sergio; WOLKMER, Maria de Fátima S. O "novo" direito à àgua no constitucionalismo da América Latina. R. Inter. Interdisc. INTERthesis, Florianópolis, v.9, n.1, p. 51-69, Jan./Jul. 2012. 
SIMÕES, Antonio José Ferreira. Integração: sonho e realidade na América do Sul. Brasília: FUNAG, 2011.

SIRVINSKAS, Luís Paulo. Manual de Direito Ambiental. 5 . Edição. São Paulo: Saraiva, 2007.

TUSSI, Matheus Gazzola. Cooperação Internacional e Recursos Hídricos: a formação de um regime internacional para o Aquífero Guarani. Dissertação (Mestrado em Ciências Sociais). Programa de Pós-Graduação em Ciências Sociais, Pontifícia Universidade Católica do Rio Grande do Sul (PUC-RS), Porto Alegre, 2008.

WOLKMER, Antônio Carlos. Introdução ao pensamento jurídico crítico. $6^{\text {a }}$ - edição. São Paulo: Saraiva, 2008.

WOLKMER, Antônio Carlos; AUGUSTIN, Sergio; WOLKMER, Maria de Fátima S. O "novo" direito à àgua no constitucionalismo da América Latina. R. Inter. Interdisc. INTERthesis, Florianópolis, v.9, n.1, p. 51-69, Jan./Jul. 2012.

WOLKMER, Maria de Fátima Schumacher; MELO, Milena Petters. O direito fundamental à água: convergência no plano internacional e constitucional. In: MELO, Alisson José Maia (Org.) ; MORAES, Germana de Oliveira (Org.) ; MARQUES JÚNIOR, William Paiva (Org.) . As águas da UNASUL na Rio+20: direito fundamental à água e ao saneamento básico, sustentabilidade, integração da América do Sul, novo constitucionalismo latino-americano e sistema brasileiro. 01. ed. Curitiba, Paraná: Editora CRV, 2013. 